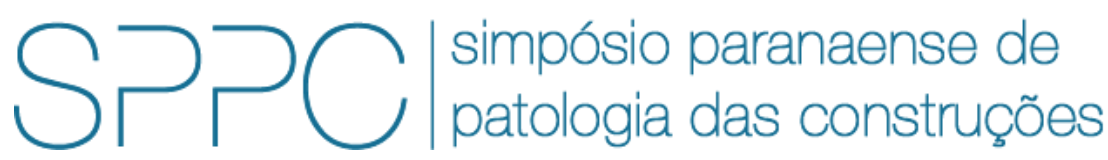

ISSN 2526-7248 artigo 2SPPC1015, pp. 171-184, 2017

\title{
Utilização do ensaio pull off na determinação da resistência à compressão de concretos comparando com outros ensaios não destrutivos
}

\author{
Mauro Vitor Grego Tavora ${ }^{1}$, Isaac Aguiar Oliveira², Dayane de Cristo Miranda ${ }^{3}$, Marcelo Henrique \\ Farias de Medeiros ${ }^{4}$ \\ ${ }^{1}$ Mestrando do Programa de Pós Graduação em Engenharia e Construção Civil, UFPR, \\ mauro.tavora@gmail.com \\ ${ }^{2}$ Mestrando do Programa de Pós Graduação em Engenharia e Construção Civil, UFPR, \\ zacaguiar@gmail.com \\ ${ }^{3}$ Estudante de Engenharia Civil, UFPR, daymiranda05@gmail.com \\ ${ }^{4}$ Doutor, Universidade Federal do Paraná, medeiros.ufpr@gmail.com
}

\begin{abstract}
Resumo: A inspeção de estruturas de concreto demanda com frequência a determinação da resistência à compressão dos concretos in loco e, para tal, podem ser aplicadas técnicas não destrutivas que evitam danos significativos na estrutura durante o ensaio. Neste contexto, para verificar a adequabilidade do pull off como ferramenta de inspeção de concretos, o mesmo foi comparado com outras duas metodologias, esclerometria e ultrassom, também técnicas não destrutivas. As três

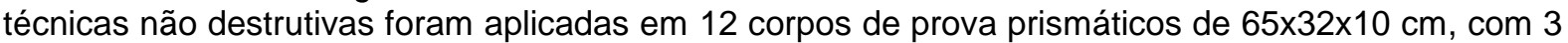
classes de resistência distintas (C20, C30 e C40). Seus resultados foram correlacionados com a resistência à compressão dos concretos, determinada por meio da ruptura de corpos de prova cilíndricos de $10 \times 20 \mathrm{~cm}$. As correlações se mostraram satisfatórias para os três ensaios. O pull off apresentou alto índice de correlação $\left(R^{2}=0,91\right)$, porém inferior às outras duas técnicas: esclerometria $\left(R^{2}=0,98\right)$ e o ultrassom $\left(R^{2}=0,99\right)$.
\end{abstract}

Palavras-chave: inspeção de estruturas de concreto; ensaios não destrutivos; esclerometria; ultrassom; pull off.

Abstract: Inspection of concrete structures often demands the determination of the compressive strength of concrete in loco, and for that, non-destructive techniques may be applied to avoid significant damage in the structure during the tests. In this context, to verify the suitability of pull off as a concrete inspection tool, it was compared with two other methodologies, rebound hammer test and ultrasonic test, also non-destructive techniques. The three non-destructive techniques were applied in 12 prismatic specimens $(65 \times 32 \times 10 \mathrm{~cm})$ with three different compressive strength classes $(\mathrm{C} 20, \mathrm{C} 30$ and C40). Their results were correlated with the compressive strength of the concretes, determined by the rupture of cylindrical specimens $(10 \times 20 \mathrm{~cm})$. Correlations were satisfactory for all three tests. The pull off test presented a high correlation $\left(\mathrm{R}^{2}=0.91\right)$, but lower than the other two techniques: rebound hammer test $\left(R^{2}=0.98\right)$ and ultrasonic test $\left(R^{2}=0.99\right)$.

Keywords: inspection of concrete structures; non-destructive tests; rebound hammer test; ultrasonic test; pull off. 
TAVORA, M. V. G.; ET AL., UTILIZAÇÃO DO ENSAIO PULL OFF NA DETERMINAÇÃO DA RESISTÊNCIA À COMPRESSÃO DE CONCRETOS COMPARANDO COM OUTROS ENSAIOS NÃO DESTRUTIVOS. $2^{\circ}$ Simpósio Paranaense de Patologia das Construções (2 SPPC), artigo 2SPPC1015, pp. 171-184, 2017. DOI: 10.4322/2SPPC.2017.015

\section{Introdução}

Uma das propriedades mais importantes do concreto armado é a sua resistência à compressão, sendo este um dos principais parâmetros utilizados para 0 dimensionamento de estruturas. Determinar esta propriedade mecânica em estruturas já acabadas, sem causar danos à sua superfície ou funcionalidade, são preocupações atuais dos profissionais da engenharia [1].

A resistência à compressão é determinada de forma simples, a partir da ruptura de corpos de prova (cps) por compressão axial. Os cps são moldados em paralelo às concretagens de uma obra e, após o tempo necessário para o endurecimento e elevação de resistência do concreto, as amostras são enviadas a um laboratório para o ensaio de caracterização. Assim, com os resultados dos ensaios de resistência à compressão simples, pode-se verificar se o concreto atingiu a resistência mínima almejada em projeto.

Para seguir essa sequência de ações, é necessário prever a moldagem de corpos de prova e, portanto, não se aplica a estruturas de concreto já executadas, como, por exemplo, edifícios antigos, onde por qualquer razão se vê necessária a determinação da resistência à compressão do concreto com o qual a estrutura foi executada. Para tal, foram desenvolvidas técnicas alternativas, com as quais é possível estimar a resistência à compressão, a partir de ensaios in loco e correlações com outras propriedades.

Conhecidos como ensaios não destrutivos ou semidestrutivos, essas técnicas vêm contrapor a necessidade de retirada de testemunhos, que por sua vez danificam a estrutura e em alguns casos é impraticável, por questões estruturais ou mesmo físicas, como por exemplo, regiões da estrutura pouco acessíveis ao equipamento de extração. Uma técnica bastante conhecida e já normatizada no Brasil é a esclerometria [2], porém esse método apresenta resultados com grande variação de valores, colocando sempre em dúvida a sua acuidade e necessitando sempre de uma complementação com outras técnicas, como por exemplo o ultrassom [3].

O pull off é também uma técnica não-destrutiva, que já está normatizada no Brasil no campo de argamassas, porém pouco explorada no âmbito da determinação das propriedades dos concretos. Essa técnica se baseia na correlação entre a resistência à tração do concreto - determinada a partir da força de arrancamento, que consiste na força necessária para arrancar um disco colado na superfície do concreto - e a resistência à compressão do mesmo.

Um estudo sobre pull off comparando-o com outras técnicas convencionais aplicadas em concretos se mostra bastante relevante, pois, este ensaio pode ser uma alternativa às técnicas utilizadas atualmente para estimar a resistência à compressão do concreto ou ainda ajudar a corroborar os resultados de outros ensaios.

Além disso, considerando que as estruturas de concreto possuem um tempo de vida útil, que segundo a ISO 13823:2008 [4] é "o período efetivo de tempo durante o qual uma estrutura ou qualquer de seus componentes satisfazem os requisitos de desempenho do projeto, sem ações imprevistas de manutenção ou reparo" e que os primeiros prédios altos com estrutura em concreto armado no Brasil datam da década de 1920 [5] muitos desses edifícios se encontram em estado de envelhecimento 
TAVORA, M. V. G.; ET AL., UTILIZAÇÃO DO ENSAIO PULL OFF NA DETERMINAÇÃO DA RESISTÊNCIA À COMPRESSÃO DE CONCRETOS COMPARANDO COM OUTROS ENSAIOS NÃO DESTRUTIVOS. $2^{\circ}$ Simpósio Paranaense de Patologia das Construções (2 SPPC), artigo 2SPPC1015, pp. 171-184, 2017. DOI: 10.4322/2SPPC.2017.015

avançado, e devem ser inspecionados, para se verificar se os mesmos ainda possuem condições de desempenhar suas funções, garantindo a segurança de seus usuários. Portanto, uma técnica eficiente e prática para a determinação das características mecânicas das estruturas em concreto armado se mostra indispensável neste cenário.

Logo, esse trabalho tem como objetivo geral estudar o ensaio pull off como ferramenta na estimativa da resistência à compressão de concretos, comparando-o com outros ensaios, de forma a apresentá-lo como uma opção prática para a área de inspeções de estruturas de concreto armado.

\section{Ensaios não destrutivos}

Historicamente, a resistência mecânica do concreto é o parâmetro mais empregado para se avaliar a qualidade do material [6] e para medir essa propriedade podem ser empregados diversos métodos, que, por sua vez, podem ser englobados em duas classes principais: os ensaios destrutivos e os ensaios não-destrutivos.

Os ensaios destrutivos são empregados em maior escala, em função da sua praticidade, rapidez na obtenção dos resultados e baixo custo. Os ensaios nãodestrutivos não danificam a estrutura, entretanto, a resistência do concreto não é mensurada de forma direta, e sim a partir de correlações com outras propriedades do material. Essas técnicas são mais aplicadas na área de investigação de estruturas em uso, quando há sinais de comprometimento nos elementos estruturais, que podem estar ligados a uma resistência inadequada do concreto. Geralmente, estas técnicas são mais complexas, pois exigem equipamentos mais sofisticados e mão de obra qualificada para a obtenção e interpretação dos resultados [6].

\subsection{Esclerometria}

A esclerometria é um método que consiste em impactar a superfície do elemento concreto, por meio de um equipamento conhecido por Martelo de Schmidt ou esclerômetro (Figura 1). Em seguida mede-se o recuo do martelo que é correlacionado com a resistência à compressão. No Brasil, o procedimento de ensaio é estabelecido pela NBR 7584 [2].

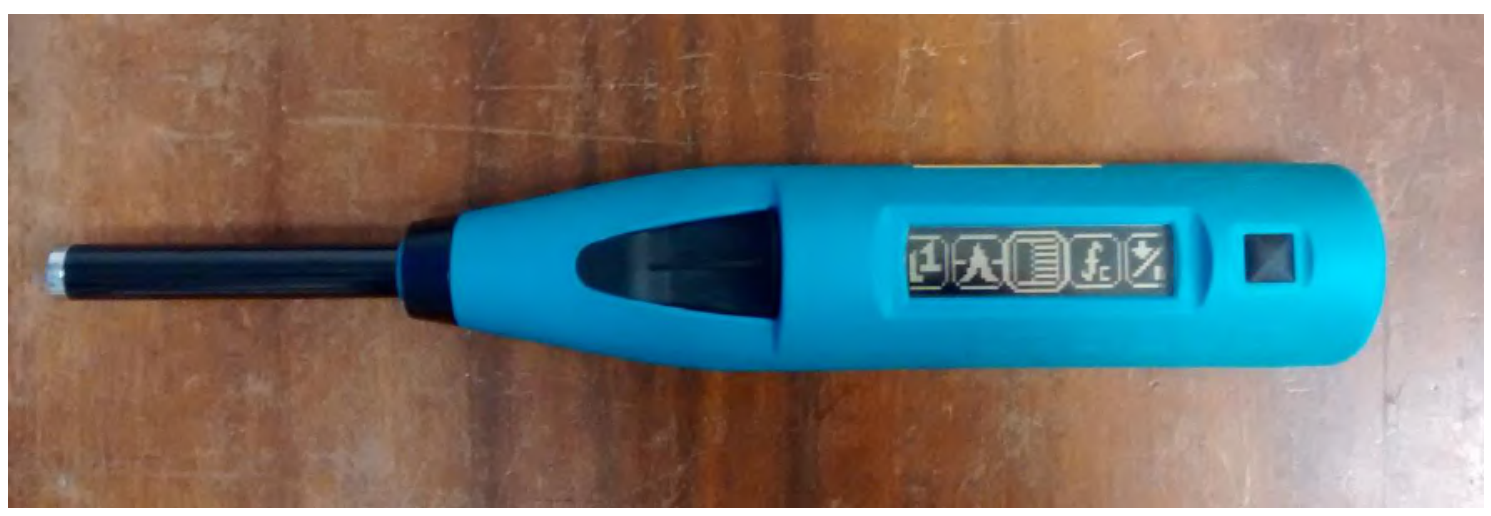

Figura 1: Martelo de Schmidt ou Esclerômetro 
TAVORA, M. V. G.; ET AL., UTILIZAÇÃO DO ENSAIO PULL OFF NA DETERMINAÇÃO DA RESISTÊNCIA À COMPRESSÃO DE CONCRETOS COMPARANDO COM OUTROS ENSAIOS NÃO DESTRUTIVOS. $2^{\circ}$ Simpósio Paranaense de Patologia das Construções (20 SPPC), artigo 2SPPC1015, pp. 171-184, 2017. DOI: 10.4322/2SPPC.2017.015

Embora a esclerometria seja uma técnica rápida e de baixo custo, ela possui algumas exigências para que os seus resultados sejam confiáveis. O equipamento deve ser utilizado somente em superfícies lisas e elementos imóveis e não deverão ser ensaiados concretos com idades baixas ou resistências abaixo de $7 \mathrm{MPa}$, pois a superfície pode vir a ser danificada pelo martelo [7].

Outros fatores como grau de umidade do concreto e características dos agregados podem distorcer os resultados [2] e, além disso, superfícies carbonatadas podem elevar os valores estimados pelo esclerômetro. Segundo Réus [8] o fenômeno da carbonatação eleva os resultados devido à colmatação dos poros do concreto na zona carbonatada, influenciando diretamente os resultados obtidos pela esclerometria. A NBR 7584 [2], que regulamenta este ensaio, indica que os valores obtidos com o ensaio em superfícies carbonatadas podem ser superestimados em até 50\%. Levando em consideração que em estruturas antigas há uma grande chance das superfícies dos elementos de concreto estarem carbonatadas, os resultados da esclerometria não representariam o interior dos elementos tornando necessária a complementação desta metodologia com outras técnicas, como o ultrassom. Essa complementação com outras técnicas aumentam o custo e o tempo de execução, atenuando, assim, a suas principais vantagens da esclerometria.

\subsection{Ultrassom}

No Brasil, o procedimento de ensaio pelo método do ultrassom é estabelecido pela NBR 8802 [3]. Com as leituras de velocidade de ultrassom (Figura 2) é possível elaborar correlações com a resistência à compressão do concreto e usar este gráfico para estimar a resistência de outras áreas sem extrair testemunhos, que é caro e demorado.

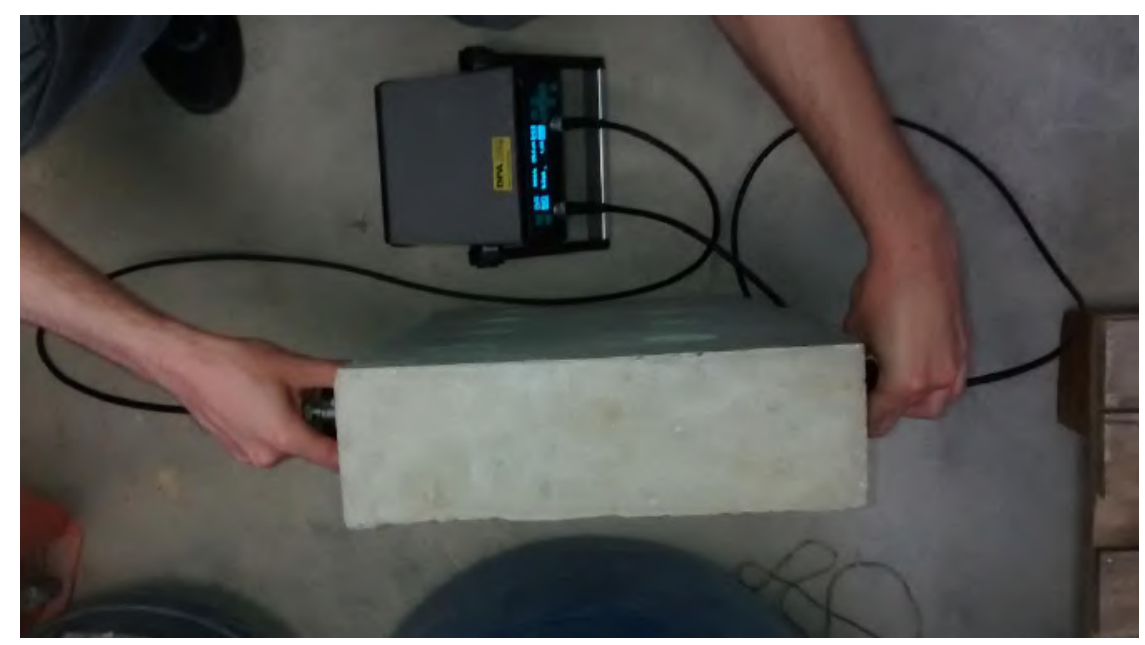

Figura 2: Equipamento do ensaio de ultrassom

Diferente da esclerometria, esse método abranje o interior dos elementos e não somente a superficie, porém, o teor de umidade do concreto a ser ensaiado é responsável por variações significativas, que devem ser consideradas para uma correta correlação e estimativa da resistência à compressão do concreto. Outras variações na velocidade do pulso podem ocorrer devido a condições distintas de cura e hidratação do cimento ou à presença de água livre nos poros e vazios do concreto [7]. 
TAVORA, M. V. G.; ET AL., UTILIZAÇÃO DO ENSAIO PULL OFF NA DETERMINAÇÃO DA RESISTÊNCIA À COMPRESSÃO DE CONCRETOS COMPARANDO COM OUTROS ENSAIOS NÃO DESTRUTIVOS. $2^{\circ}$ Simpósio Paranaense de Patologia das Construções (20 SPPC), artigo 2SPPC1015, pp. 171-184, 2017. DOI: 10.4322/2SPPC.2017.015

Além da umidade, Pereira \& Medeiros [1] afirmam que outros fatores importantes podem influenciar na velocidade de propagação, como comprimento de percurso, dimensões da peça a ensaiar, presença de armaduras e temperatura.

A presença de armaduras tem influência nos resultados das correlações entre a velocidade de propagação das ondas e a resistência mecânica do concreto, principalmente quando as barras de aço estão dispostas na direção de propagação [3]. Esse fato não inviabiliza, porém dificulta o uso da técnica sendo necessária uma complementação com outras técnicas, como a pacometria, que serve para localizar as armaduras para um posterior posicionamento dos transdutores, de forma a desviar das mesmas durante o ensaio.

\subsection{Pull off}

O método pull off se baseia em uma possível correlação entre a força de tração necessária para arrancar um disco metálico colado na face de um elemento de concreto, rompendo uma parcela do material, e a resistência à compressão deste concreto [9]. As suas primeiras versões foram desenvolvidas na Inglaterra, na Queen's University, no início dos anos 70, para avaliar a resistência à compressão de vigas com alto teor de alumina [10].

Para a execução do ensaio é utilizado um equipamento apoiado no concreto por meio de um tripé (Figura 3). Esse dispositivo conecta-se, por meio de uma haste com rosca, ao disco metálico pela qual é aplicada uma tensão máxima de $10 \mathrm{kN}$, em uma razão aproximadamente de $6 \mathrm{kN} / \mathrm{min}$ [10].

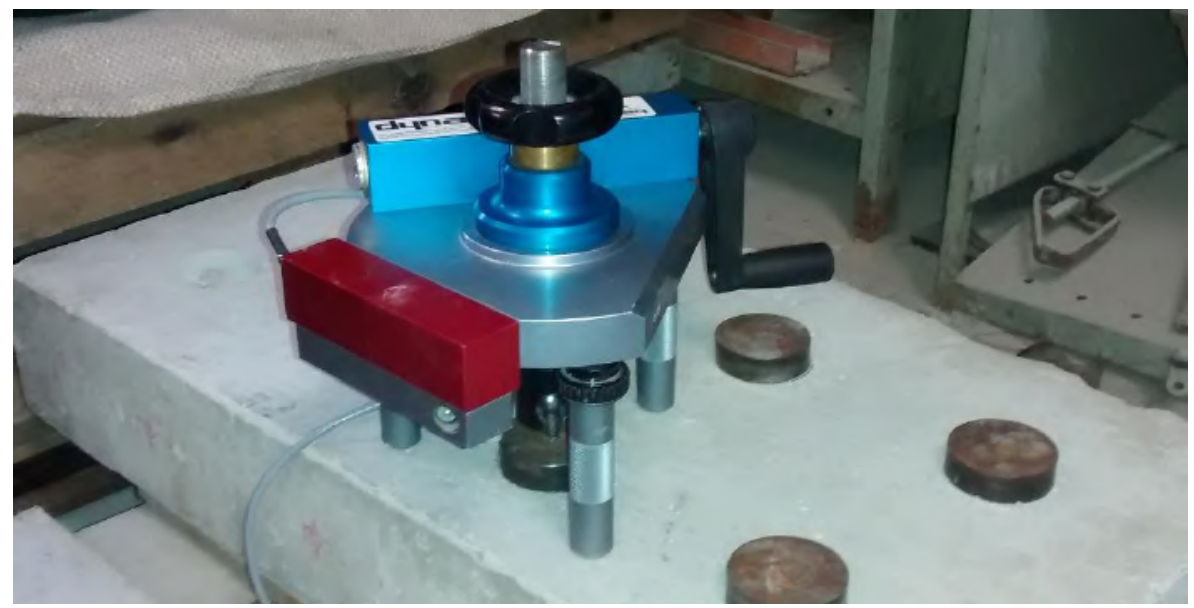

Figura 3: Equipamento para o ensaio Pull Off

O ensaio pode ser realizado de duas formas: colando o disco diretamente na superfície do concreto, obtendo-se com isso após o arrancamento uma superfície de ruptura próxima à base do disco (Figura 4a) ou então, efetuando um corte superficial em torno do disco (Figura 4b). A execução do corte pode ajudar a evitar a influência das condições da superfície do concreto, como no caso das superfícies carbonatadas [10]. 


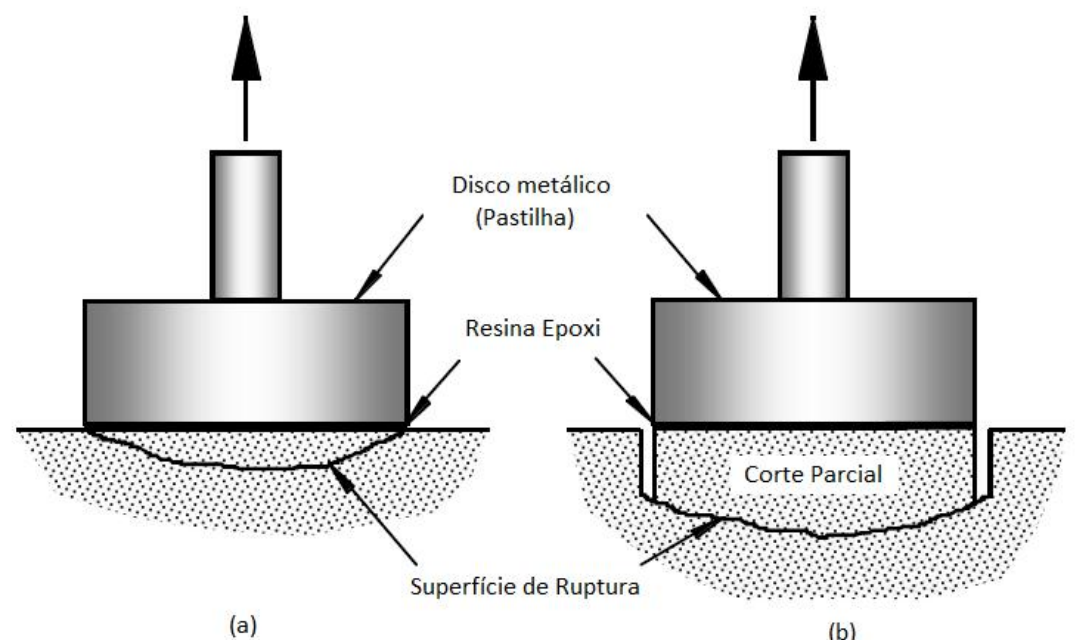

(a)

(b)

Figura 4: Formas de aplicação dos disco para o ensaio Pull Off [10]

Foi constatado por Evangelista [11] que a carga de ruptura do ensaio com a presença do corte tende a ser menor do que a do ensaio sem o corte, para concretos iguais, relacionando esta redução à concentração de tensões ao redor do corte e à ausência de concreto nesta região.

Grullón et al. [12] apud Evangelista [11] afirmam que a relação entre a força de tração e a resistência à compressão do concreto depende dos seguintes fatores: idade, tipo e dimensão máxima dos agregados, condições de cura, dosagem e tipo de cimento. Já segundo Bungey [13] apud Evangelista [11], além das propriedades do concreto, outros fatores podem influenciar os resultados, como: material do disco, diâmetro e espessura do disco, efeitos do corte feito no concreto, sistema de reação do equipamento e velocidade de aplicação de carga.

Na Europa, o pull off é normatizado pela BS 1881-207 [14], já no Brasil, este ensaio é usado, tradicionalmente, para medir a resistência de aderência de argamassas, e é normatizado pela NBR 14081-4 [15]. No momento em que se passa a usar o pull off para ensaiar elementos em concreto, deve-se levar em consideração um novo fator que é o agregado graúdo, de grande influência, e que varia em função da sua forma, posição em relação à superfície de teste e origem. Evangelista [11] constatou a necessidade de uma curva de correlação para o concreto com agregado graúdo de origem calcária e outra para concretos com agregados de basalto, cascalho, granito e arenito.

A rigidez do disco também é um parâmetro importante, pois limita a relação entre espessura e diâmetro dos discos. Essa dependência pode ser observada na Figura 5 , que mostra que para garantir uma distribuição uniforme de tensões, e consequentemente uma carga máxima de ruptura, a espessura dos discos de aço devem ser de pelo menos $40 \%$ do diâmetro do mesmo, ao passo que, no caso dos discos de alumínio, a proporção sobe para $60 \%$. Estes resultados experimentais foram estabelecidos com base em análises com elementos finitos [11]. 


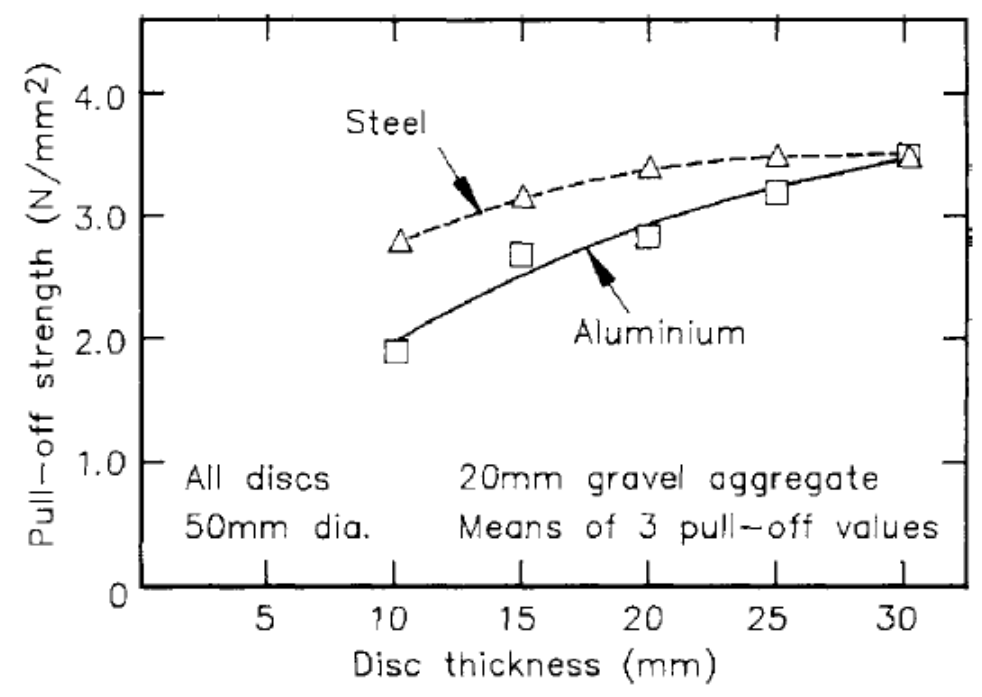

Figura 5: Tensão de arrancamento versus espessura dos discos de diferentes materiais (aço e alumínio) [13]

Antes do ensaio utilizando o pull off, a superfície do concreto deve ser preparada com lixamento e/ou desengorduramento, para garantir uma boa colagem dos discos. Os discos, por sua vez, são colados utilizando resinas Epoxi como adesivo, cuja resistência mecânica deve ser superior à do concreto em ensaio. Esses adesivos podem ainda necessitar de um processo de cura de até 24 horas, dependendo do material (tipo de resina e fabricantes) e de outras circunstâncias, como questões ambientais, no momento da fixação. Superfícies úmidas podem representar uma dificuldade durante a fixação dos discos [13]. Portanto, como desvantagens à este ensaio é importante salientar o tempo de espera necessário para a cura da cola de fixação do disco, além de ser necessário realizar um reparo nos locais onde foram realizados os arrancamentos.

\section{Materiais e métodos}

As diferentes técnicas não destrutivas foram aplicadas em corpos de prova prismáticos de $65 \times 32 \times 10 \mathrm{~cm}$, moldados com três traços de concreto com resistências distintas. Foi tomado como base, para a avaliação dessas técnicas, resultados obtidos a partir de corpos de prova cilíndricos, moldados com os mesmos concretos, e submetidos ao ensaio de resistência à compressão, conforme NBR 5739 [16].

A colagem dos discos, para o ensaio pull off, foi realizada por meio do adesivo Sikadur® 32, do fabricante Sika, que pode atingir uma resistência à compressão de $60 \mathrm{MPa}$ em 1 dia, e uma resistência de aderência de 3,80 MPa com o concreto e 3,30 MPa com o aço, ambas aos 7 dias.

Os concretos foram confeccionados utilizando cimento Portland tipo CP V ARI-RS, cuja composição consiste em 0 - 5\% de calcário e $95-100 \%$ de clínquer + gesso, e como agregados uma areia média, natural de rio e uma brita de origem calcária, secos 
TAVORA, M. V. G.; ET AL., UTILIZAÇÃO DO ENSAIO PULL OFF NA DETERMINAÇÃO DA RESISTÊNCIA À COMPRESSÃO DE CONCRETOS COMPARANDO COM OUTROS ENSAIOS NÃO DESTRUTIVOS. $2^{\circ}$ Simpósio Paranaense de Patologia das Construções (20 SPPC), artigo 2SPPC1015, pp. 171-184, 2017. DOI: 10.4322/2SPPC.2017.015

em estufa a $100^{\circ} \mathrm{C}$, cujas características são apresentadas na Tabela 1Erro! Fonte de referência não encontrada..

Tabela 1: Características dos agregados

\begin{tabular}{ccc}
\hline Agregado & Miúdo & Graúdo \\
\hline $\begin{array}{c}\text { Dimensão máxima característica } \\
(\mathrm{mm})\end{array}$ & - & 19 \\
$\begin{array}{c}\text { Massa unitária } \\
\left(\mathrm{Kg} / \mathrm{dm}^{3}\right)\end{array}$ & 1,34 & 1,45 \\
$\begin{array}{c}\text { Massa específica } \\
\left(\mathrm{Kg} / \mathrm{dm}^{3}\right)\end{array}$ & 2,57 & 2,81 \\
$\begin{array}{c}\text { Material Pulverulento } \\
(\%)\end{array}$ & 5,1 & 1,3 \\
\hline
\end{tabular}

\subsection{Dosagem, moldagem e cura}

Para atingir as classes de concreto almejadas, C20, C30 e C40, foi realizado um estudo de dosagem experimental, com os materiais citados, baseado no método IPTEPUSP estabelecendo os traços para cada concreto. As concretagens foram realizadas utilizando uma betoneira elétrica de capacidade para 120 litros e adensamento manual.

Foram moldados quatro corpos de prova prismáticos de $65 \times 32 \times 10 \mathrm{~cm}$ e seis corpos de prova cilíndricos, com dimensões $10 \times 20 \mathrm{~cm}$, para cada classe de concreto.

Tanto os corpos de prova prismáticos quanto os cilíndricos foram submetidos à uma cura submersa em um tanque durante 7 dias, e, após esse período, completaram-se os 28 dias ao ar livre.

\subsection{Ensaios}

\subsubsection{Compressão}

Os corpos de prova cilíndricos foram retificados e em seguida ensaiados em uma prensa hidráulica da marca EMIC NBR 5739 [14].

\subsubsection{Esclerometria}

Os ensaios foram realizados utilizando um esclerômetro da marca Proceq, modelo Silver Schmidt PC N, seguindo as recomendações da NBR 7584 [2]. A aplicação foi feita nas duas maiores faces laterais dos blocos, totalizando 16 leituras ao longo de cada uma, distribuídas uniformemente ao longo da superfície, distando, no mínimo, $50 \mathrm{~mm}$ das bordas e $30 \mathrm{~mm}$ entre centros de pontos de impacto.

As faces, durante os ensaios, se encontravam sempre em posição horizontal, e o equipamento perpendicular em relação às superfícies, em posição vertical.

\subsubsection{Ultrassom}


TAVORA, M. V. G.; ET AL., UTILIZAÇÃO DO ENSAIO PULL OFF NA DETERMINAÇÃO DA RESISTÊNCIA À COMPRESSÃO DE CONCRETOS COMPARANDO COM OUTROS ENSAIOS NÃO DESTRUTIVOS. $2^{\circ}$ Simpósio Paranaense de Patologia das Construções (2 SPPC), artigo 2SPPC1015, pp. 171-184, 2017. DOI: 10.4322/2SPPC.2017.015

O equipamento utilizado para o ensaio de ultrassom é da marca Proceq, modelo PUNDIT LAB, com transdutores de $54 \mathrm{kHz}$.

Foram realizadas três leituras para cada bloco, nas faces laterais, posicionando os transdutores de forma a se obterem somente transmissões diretas das ondas.

\subsubsection{Pull off}

O equipamento utilizado para o ensaio pull off é da marca Proceq, modelo Dyna Z 16E e os discos utilizados são de aço com $50 \mathrm{~mm}$ de diâmetro e espessura de 20 $\mathrm{mm}$.

Foram realizados 8 arrancamentos em cada bloco, totalizando 32 arrancamentos para cada classe de concreto. Antes da colagem dos discos, foram executados cortes no concreto, em cada ponto de arrancamento, utilizando uma furadeira manual equipada com serra-corpo atingindo uma profundidade de aproximadamente $20 \mathrm{~mm}$. Além disso, as superfícies dos blocos também receberam um lixamento mecânico para melhorar a colagem dos discos. A colagem dos discos foi executada na face superior dos blocos (maior face), respeitando-se as distâncias mínimas de $50 \mathrm{~mm}$ (um diâmetro) das bordas e $100 \mathrm{~mm}$ (dois diâmetros) entre discos, na qual foi utilizado 0 adesivo Epoxi, 48 horas antes dos ensaios.

\subsubsection{Tratamento estatístico}

Após finalizar todos os experimentos, os resultados foram submetidos a um tratamento estatístico eliminando valores inconsistentes, que poderiam comprometer a validade das análises. Este tratamento consistiu em calcular a média geral de cada amostra, em seguida descartou-se valores que extrapolavam o intervalo limitado pelo desvio-padrão, para depois a média ser recalculada somente com os valores válidos.

\section{Resultados e Discussão}

A partir dos valores obtidos por meio dos ensaios experimentais, após o tratamento estatístico, dispostos na Tabela 2, foi possível estabelecer gráficos de correlação entre os resultados dos ensaios de compressão simples e demais ensaios não destrutivos (Figura 6, Figura 7, Figura 8).

Tabela 2: Valores médios do resultado final dos ensaios

\begin{tabular}{ccccc}
\hline Classe & $\begin{array}{c}\text { Compressão } \\
\text { (MPa) }\end{array}$ & $\begin{array}{c}\text { Pull Off } \\
\text { (MPa) }\end{array}$ & Esclerometria & $\begin{array}{c}\text { Ultrassom } \\
\text { (m/s) }\end{array}$ \\
\hline C 20 & 22,98 & 2,14 & 38,07 & 4558,92 \\
C 30 & 29,38 & 2,59 & 41,58 & 4691,25 \\
C 40 & 37,28 & 2,78 & 48,85 & 4824,25 \\
\hline
\end{tabular}


TAVORA, M. V. G.; ET AL., UTILIZAÇ̃̃O DO ENSAIO PULL OFF NA DETERMINAÇÃO DA RESISTÊNCIA À COMPRESSÃO DE CONCRETOS COMPARANDO COM OUTROS ENSAIOS NÃO DESTRUTIVOS. $2^{\circ}$ Simpósio Paranaense de Patologia das Construções (20 SPPC), artigo 2SPPC1015, pp. 171-184, 2017. DOI: 10.4322/2SPPC.2017.015

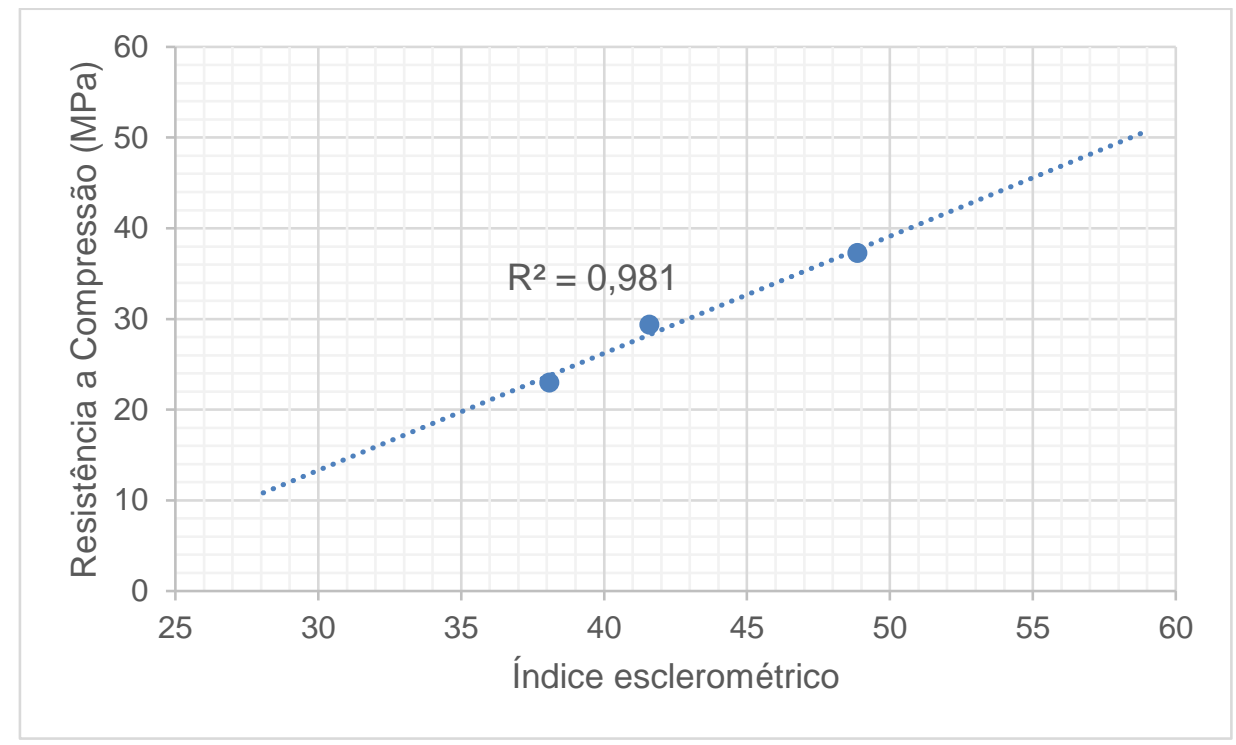

Figura 6: Correlação entre Resistência à Compressão x Índice esclerométrico

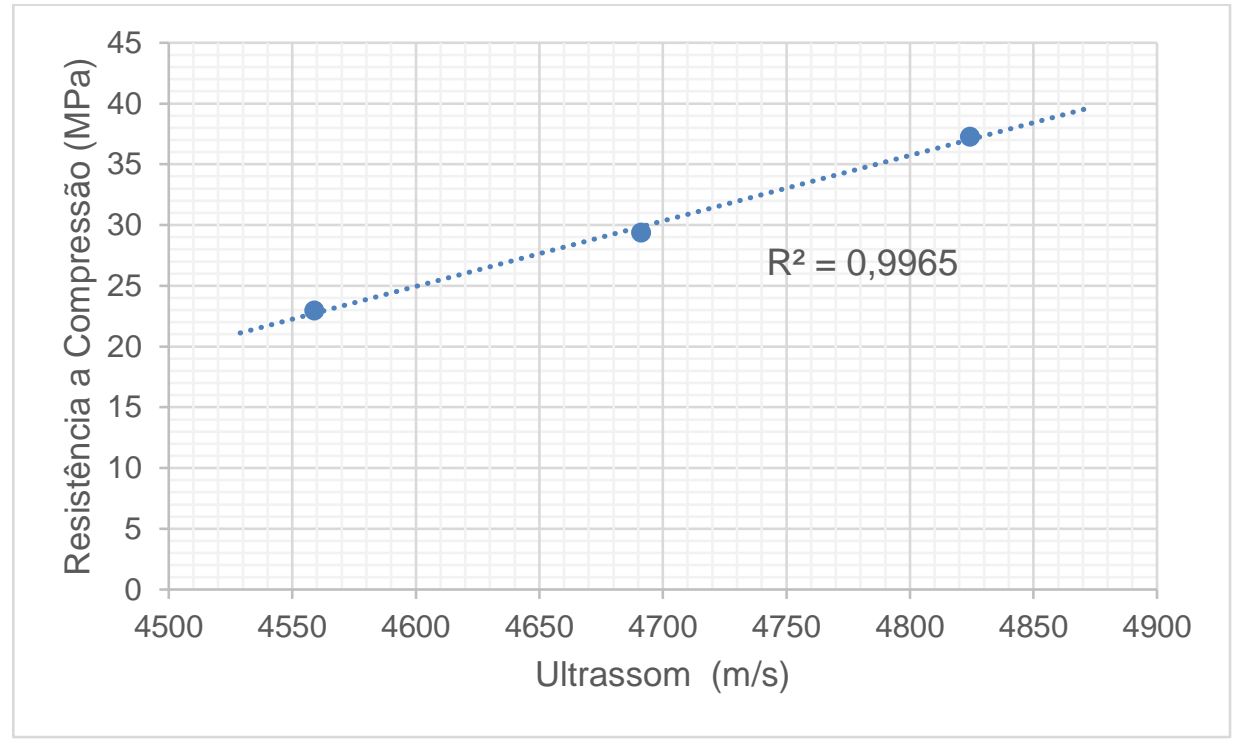

Figura 7: Correlação entre Resistência à Compressão x Velocidade de ultrassom 
TAVORA, M. V. G.; ET AL., UTILIZAÇ̃̃O DO ENSAIO PULL OFF NA DETERMINAÇÃO DA RESISTÊNCIA À COMPRESSÃO DE CONCRETOS COMPARANDO COM OUTROS ENSAIOS NÃO DESTRUTIVOS. $2^{\circ}$ Simpósio Paranaense de Patologia das Construções (20 SPPC), artigo 2SPPC1015, pp. 171-184, 2017. DOI: 10.4322/2SPPC.2017.015

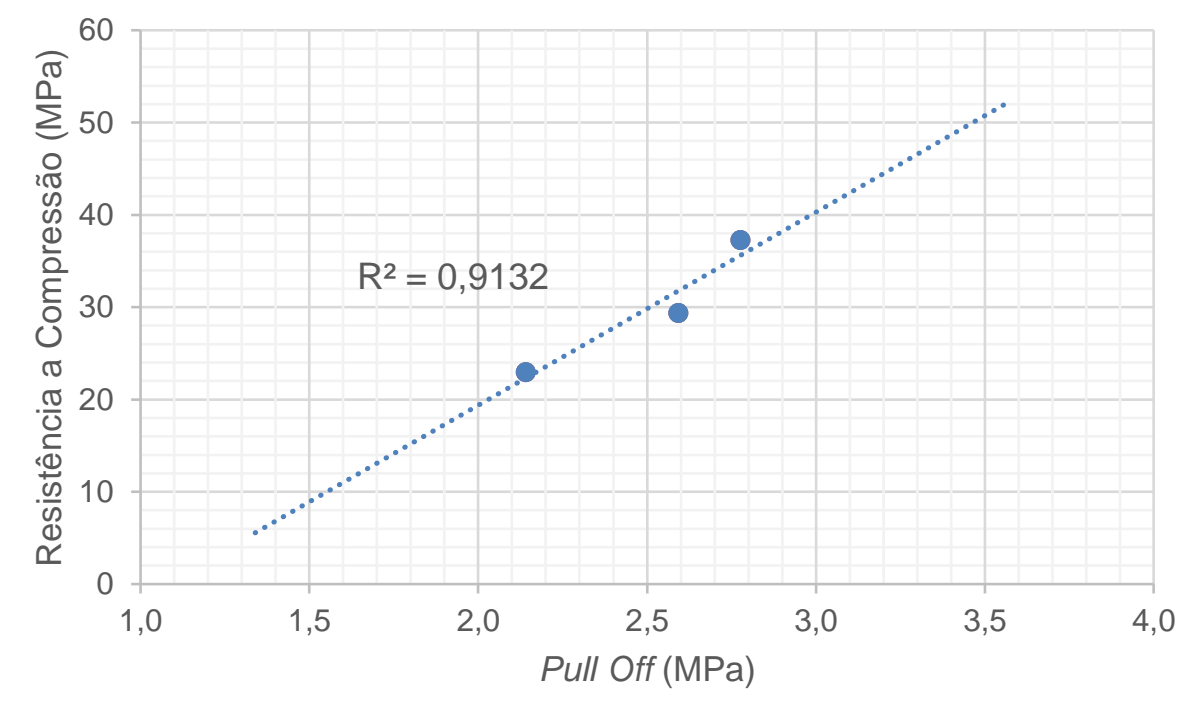

Figura 8: Correlação entre Resistência à Compressão x Resistência no Pull Off

Diante dos resultados e divergindo da constatação de alguns autores como Bertolini [17], a correlação entre os resultados da esclerometria e do ensaio de resistência à compressão se mostrou satisfatória, próxima à correlação com o Ultrassom, confirmando a possibilidade de se usar as duas técnicas em conjunto com o intuito de refinar resultados.

Entretanto, a correlação utilizando os resultados do ensaio pull off, apesar de não ter sido ruim, mostrou-se inferior às anteriores. Com esse resultado, torna-se interessante revisar os fatores, que, segundo Evangelista [11], poderiam ter influenciado os resultados. Foram utilizados discos de um mesmo material, diâmetro, espessura e ainda a velocidade de carga também foi a mesma para todos os arrancamentos. Os cortes realizados no concreto foram feitos pelo mesmo operador, utilizando o mesmo tipo de equipamento e alcançando uma profundidade de $20 \pm 2$ $\mathrm{mm}$, não devendo ser a causa de alterações na correlação. Todavia, ao utilizar uma furadeira manual, os cortes demandaram grande energia do operador, podendo causar algum tipo de dano ao concreto, refletindo nos resultados.

Uma das vantagens desta metodologia, comentada por Pereira \& Medeiros (2012) [1], seria a possibilidade de observar resultados não satisfatórios por meio da superfície de ruptura. Para tanto, se destacaram as seguintes possibilidades de ocorrência durante os 128 arrancamentos:

- Ruptura regular, na qual, aderida ao disco metálico, a parcela de concreto extraída, contendo agregado graúdo, possui espessura de 20 $\pm 2 \mathrm{~mm}$ (Figura 9 a e b);

- Ruptura próxima à superfície, na qual a parcela de concreto extraída possui uma espessura de $7 \pm 2 \mathrm{~mm}$, e não contém agregado graúdo ( Figura 10); 
TAVORA, M. V. G.; ET AL., UTILIZAÇÃO DO ENSAIO PULL OFF NA DETERMINAÇÃO DA RESISTÊNCIA À COMPRESSÃO DE CONCRETOS COMPARANDO COM OUTROS ENSAIOS NÃO DESTRUTIVOS. $2^{\circ}$ Simpósio Paranaense de Patologia das Construções (2 SPPC), artigo 2SPPC1015, pp. 171-184, 2017. DOI: 10.4322/2SPPC.2017.015

- Disco não centrado, situação que, durante a colagem dos discos houve deslocamento dos mesmos, de forma que a área de aderência se reduziu influenciando diretamente na tensão de arrancamento (Figura 11Erro! Fonte de referência não encontrada.);

- Ruptura na cola, na qual o concreto não se rompe e a ruptura ocorre na interface entre a cola e o concreto ou entre a cola e o disco metálico (Figura 12);
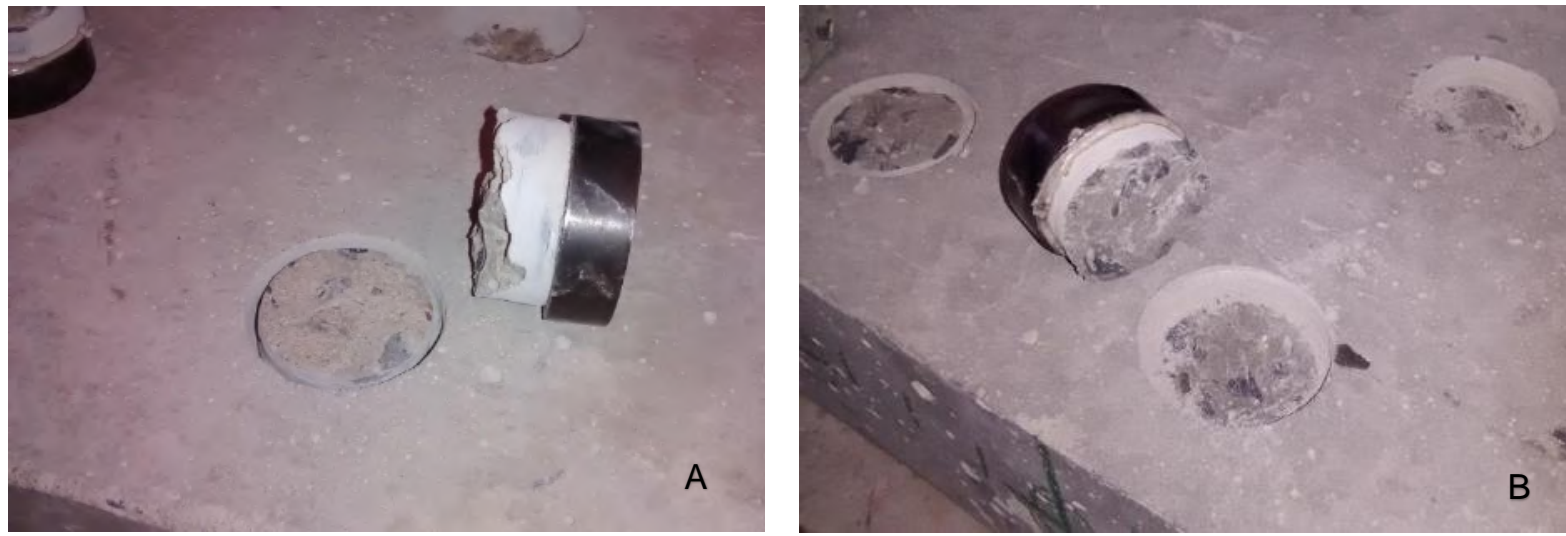

Figura 9: Ruptura regular

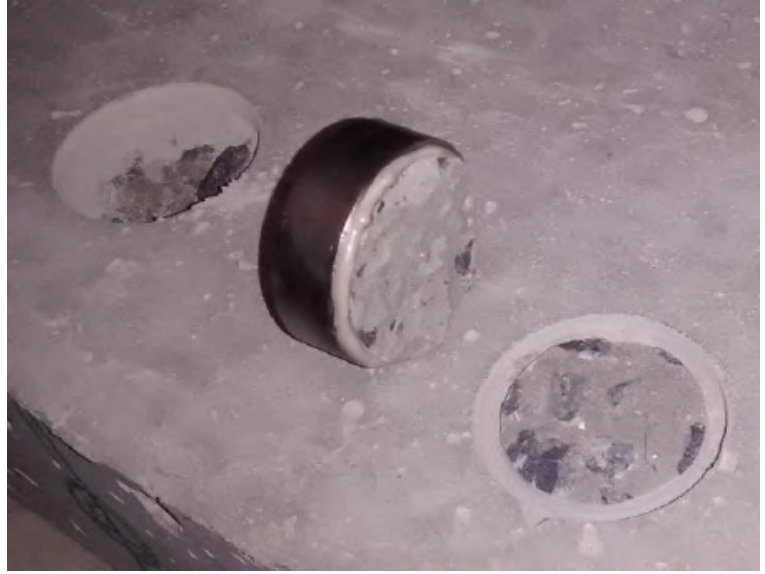

Figura 10: Ruptura próxima à superfície

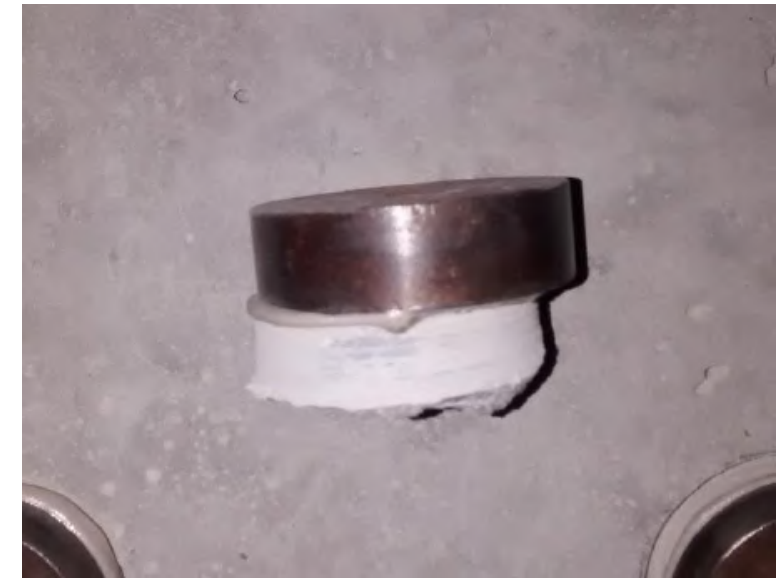

Figura 11: Deslocamento do disco

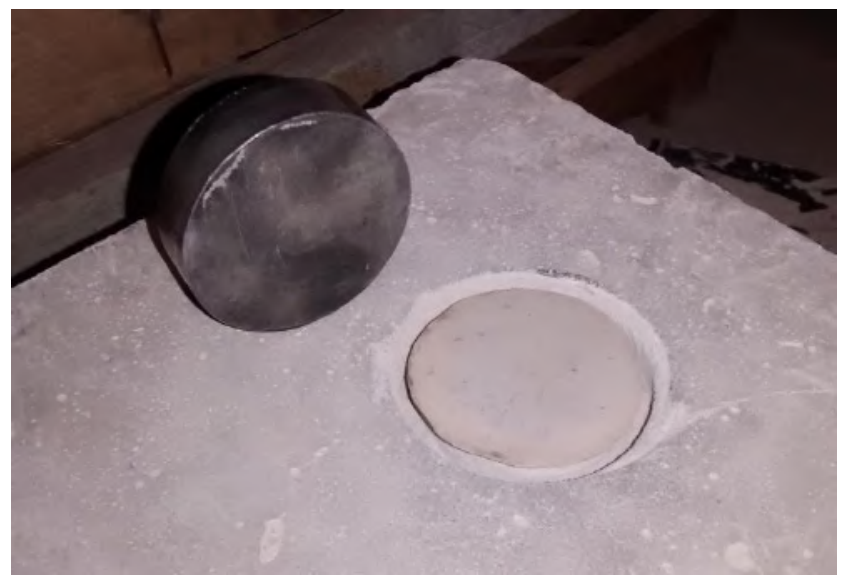

Figura 12: Ruptura na cola 
TAVORA, M. V. G.; ET AL., UTILIZAÇÃO DO ENSAIO PULL OFF NA DETERMINAÇÃO DA RESISTÊNCIA À COMPRESSÃO DE CONCRETOS COMPARANDO COM OUTROS ENSAIOS NÃO DESTRUTIVOS. $2^{\circ}$ Simpósio Paranaense de Patologia das Construções (20 SPPC), artigo 2SPPC1015, pp. 171-184, 2017. DOI: 10.4322/2SPPC.2017.015

As ocorrências de deslocamento do disco, ruptura na cola e outros problemas representaram, respectivamente, 5,5\%, 3,1\% e 3,9\% do total de arrancamentos, e seus resultados foram desconsiderados nas análises. Rupturas próximas à superfície representaram $10,2 \%$ e rupturas regulares $77,3 \%$, somando $87,5 \%$ dos resultados do total de arranchamentos.

\section{Conclusão}

O presente trabalho demonstrou, por meio dos seus experimentos, que é possível estabelecer uma correlação entre os resultados do ensaio pull off com a resistência à compressão, com uma margem de precisão adequada. Porém, nestes experimentos, dentro de suas condições e variáveis próprias, a correlação com os resultados do pull off se mostrou inferior, se comparada com as outras duas técnicas não destrutivas empregadas: esclerometria e ultrassom. Portanto, em uma situação onde seja necessária a estimativa da resistência à compressão de um concreto, de uma estrutura pré-existente, e na qual o cenário de atuação seja semelhante às condições estabelecidas nos experimentos, é possível que a utilização da esclerometria ou do ultrassom, como técnicas não destrutivas, sejam mais eficientes que a técnica do pull off.

\section{Referências}

[1] Pereira, E.; Medeiros, M. H. F. (2012). "Pull Off test to evaluate the compressive strength of concrete: an alternative to Brazilian standard techniques Ensaio de ' Pull Off' para avaliar a resistência à normalizados no Brasil", Struct. Mater., vol. 5, no. 6, pp. 757-768.

[2] ABNT NBR 7584 (1985) - Concreto endurecido - avaliação da dureza superficial pelo esclerômetro de reflexão. Associação Brasileira de Normas Técnicas. pp. 3-5.

[3] ABNT NBR 8802 (1992) - Concreto endurecido - Determinação da velocidade de propagação de onda. Associação Brasileira de Normas Técnicas, p. 8.

[4] ESA ISO 13823 (2008) - "General principles on the design of structure for durability", vol. 13823.

[5] Loturco, B. (2008) Sinônimo de construção. [Online]. Link de acesso: http://techne.pini.com.br/engenharia-civil/137/artigo287574-1.aspx. [Accessed: 04-Mar-2017].

[6] Andrade, J. J.; Tutikian, B. F. (2011) Concreto: Ciência e Tecnologia. São Paulo: G. C. Isaias.

[7] IAEA (2002), "Guidebook on non-destructive testing concrete structures", Vienna.

[8] Réus, G. C.; Souza, D. J.; Silvestro, L.; Gomes, G. R.; Medeiros, M. H. F.; Filho, M. L. S. (2016) Influência da frente de carbonatação na resistência superficial do concreto obtida pelo método da esclerometria, Belém-PA, pp. 861-870.

[9] Castro, A. L.; Ângulo, S. C.; Bilesky, P. C.; Santos, R. F.; Hamassaki, L. T.; Silva, E. (2009) Métodos de ensaios não destrutivos para estruturas de concreto, Revista Téchne, São Paulo, p. 56 a 62. 
TAVORA, M. V. G.; ET AL., UTILIZAÇ̃̃O DO ENSAIO PULL OFF NA DETERMINAÇÃO DA RESISTÊNCIA À COMPRESSÃO DE CONCRETOS COMPARANDO COM OUTROS ENSAIOS NÃO DESTRUTIVOS. $2^{\circ}$ Simpósio Paranaense de Patologia das Construções (20 SPPC), artigo 2SPPC1015, pp. 171-184, 2017. DOI: 10.4322/2SPPC.2017.015

[10] Malhotra, V. M.; Carino, N. J. (2004) "Non-destrutive Testing of Concrete", 2nd ed. West Conshohocken.

[11] Evangelista, A. C. J. (2002) Avaliação da resistência do concreto usando diferentes ensaios não destrutivos, Tese, p. 219.

[12] Grullón, M.; Barbosa, P.; Medeiros, M. H. F.; Helene, P. (2004) Correlação entre resistência à compressão e ultra-som. Influência da dosagem e da umidade, Vol II.

[13] Bungey, J. H.; Millard, S. G. (1996) "Testing of concrete in structure", Glasgow.

[14] BS 1881 (1992) "Part 207. Testing concrete - Recommendations for the assessment of concrete strength by near-to-surface tests", Br. Stand. Inst.

[15] ABNT NBR 14081-4 (2012) - Argamassa colante industrializada para assentamento de placas cerâmicas, Parte 4: Determinação da resistência de aderência à tração. Associação Brasileira de Normas Técnicas, Rio de Janeiro.

[16] ABNT NBR 5739 (2007) - Concreto - Ensaio de compressão de corpos-de-prova cilíndricos. Associação Brasileira de Normas Técnicas. p. 9.

[17] Bertolini, L. (2006) - Materiais de Construção: patologia / reabilitação / prevenção. Oficina de Textos, São Paulo. 